\title{
Del saber tradicional a la constitución de un «habitus desarrollista» en el Norte Potosí
}

Du savoir traditionnel à la constitution d'un « habitus développementaliste » dans le Nord Potosí

From traditional knowledge to the construction of "habitus developmentalist" in Northern Potosi

\section{Claude Le Gouill}

\section{(2) OpenEdition}

\section{Journals}

Edición electrónica

URL: http://journals.openedition.org/bifea/7684

DOI: $10.4000 /$ bifea.7684

ISSN: 2076-5827

\section{Editor}

Institut Français d'Études Andines

\section{Edición impresa}

Fecha de publicación: 1 diciembre 2015

Paginación: 427-446

ISSN: 0303-7495

\section{Referencia electrónica}

Claude Le Gouill, « Del saber tradicional a la constitución de un «habitus desarrollista» en el Norte Potosí », Bulletin de l'Institut français d'études andines [En línea], 44 (3) | 2015, Publicado el 08 diciembre 2015, consultado el 05 noviembre 2020. URL : http://journals.openedition.org/bifea/7684 ; DOI : https://doi.org/10.4000/bifea.7684

\section{(c) $(1) \odot$}

Les contenus du Bulletin de l'Institut français d'études andines sont mis à disposition selon les termes de la licence Creative Commons Attribution - Pas d'Utilisation Commerciale - Pas de Modification 4.0 International. 
Bulletin de I'Institut Français d'Études Andines / 2015, 44 (3): 427-446

\title{
Del saber tradicional a la constitución de un «habitus desarrollista» en el Norte Potosí
}

\author{
Claude Le Gouill*
}

\begin{abstract}
Resumen
La región del Norte Potosí en Bolivia tiene la particularidad de ser una región minera con fuerte población indígena, donde se entrecruzaron varias ideologías y procesos de desarrollo distintos. A partir del análisis de las nociones de saber y de desarrollo en el mundo indígena, mostraremos cómo la influencia de las ONG y de los partidos políticos de izquierda llevaron a implementar un «habitus desarrollista» en las comunidades. Este habitus tiene su origen en el «campo del desarrollo» que nació en la región a través de varios proyectos de esta naturaleza y centros de formación de líderes campesinos-indígenas, quienes introdujeron nuevos saberes y visiones del desarrollo en las comunidades que se mezclaron con las visiones colectivas tradicionales.
\end{abstract}

Palabras clave: desarrollo, saberes, comunidades indígenas, O NG, Norte Potosí

\section{Du savoir traditionnel à la constitution d'un « habitus développementaliste » dans le Nord Potosí}

\section{Résumé}

La région du Nord Potosí en Bolivie a la particularité d'être une région minière à forte population indigène, où se sont entrecroisés plusieurs idéologies et processus de développement distincts. À partir de l'analyse des notions de savoir et de développement dans le monde indigène, nous montrerons comment l'influence des $\mathrm{ONG}$ et des partis politiques de gauche ont conduit à implanter un « habitus développementaliste » au sein des communautés. Cet habitus a son origine dans le « champ du développement » qui naît dans la région à travers les nombreux projets de cette nature et centres de formation de leaders paysans-indigènes, qui portèrent ces nouveaux savoirs et visions du développement dans les communautés où ils se mélangèrent aux visions collectives traditionnelles.

Doctor en Sociología del Centro de Investigación y de Documentación de las Américas (CREDA, U M R 7227) del Instituto de los Altos Estudios de América Latina (IHEAL), U niversidad París-Sorbona Nueva. Email: claudelegouill29@gmail.com 
Mots-clés : développement, savoirs, communautés indigènes, O NG, Nord Potosí

\title{
From traditional knowledge to the construction of "habitus developmentalist" in Northern Potosi
}

\begin{abstract}
The region of Northern Potosi in Bolivia has the particularity of being a mining region with a high indigenous population, where several distinct ideologies and development processes have intersected. From the analysis of the concepts of knowledge and development in the indigenous world we will show how the influence of NGO s and leftist political parties has led to the implantation of a "habitus developmentalist" within communities. This habitus has its origin in the "field of development" born in the area through the many projects of this nature and training centers for indigenous peasant leaders, who bore this new knowledge and vision of development in the communities where they intermixed with traditional collective visions.
\end{abstract}

Keywords: development, knowledges, indigenous communities, NGO, Northern Potosi

Cada año, en la comunidad de Chiro K'asa en el N orte Potosí, se realiza la ceremonia de entrega de diplomas a los nuevos bachilleres del colegio Tupak Katari, durante la cual se reúnen todos los comunarios del ayllu. Los graduados se ponen sus mejores trajes y cruzan el patio de la escuela del brazo de un pariente: el padre en el caso de las chicas; y la madre, en el de los chicos - de una manera que evoca el chacha-warmi1- para tomar espacio en el estrado, al lado de las autoridades indígenas y municipales. Durante la ceremonia, los discursos pronunciados por las autoridades subrayan el papel crucial de la educación. Las autoridades incitan a los jóvenes a seguir sus estudios en las universidades, a «hacerse profesionales» y a regresar al ayllu para traer el desarrollo. Después de la ceremonia, comienza una celebración que durará toda la noche, en la que los bachilleres invitan a la población a las casas de sus padres a comer y tomar cervezas y alcohol -0 refrescos, para los evangélicos- al ritmo de la cumbia y del reggaeton. A cambio, los invitados les regalan frazadas, materiales de cocina o muebles, del mismo modo que se hace en los matrimonios. El diploma parece de hecho sustituir el matrimonio en el paso a la edad adulta y al acceso a las responsabilidades (fig. 1).

Esta ceremonia es, hoy día, según los comunarios mismos, una de las fiestas más importantes del ayllu, después del Carnaval y del «cabildo» (durante el cual se paga la tasa territorial). La importancia que esta celebración ha adquirido es muestra de que la educación se ha vuelto central en el mundo indígena hoy, tanto para el estudiante como para la comunidad. Para el primero, marca un rito de

1 El chacha-warmi es un término aimara que designa el dualismo simbólico hombre-mujer y se refiere a la unión de dos seres humanos opuestos a través del matrimonio. 


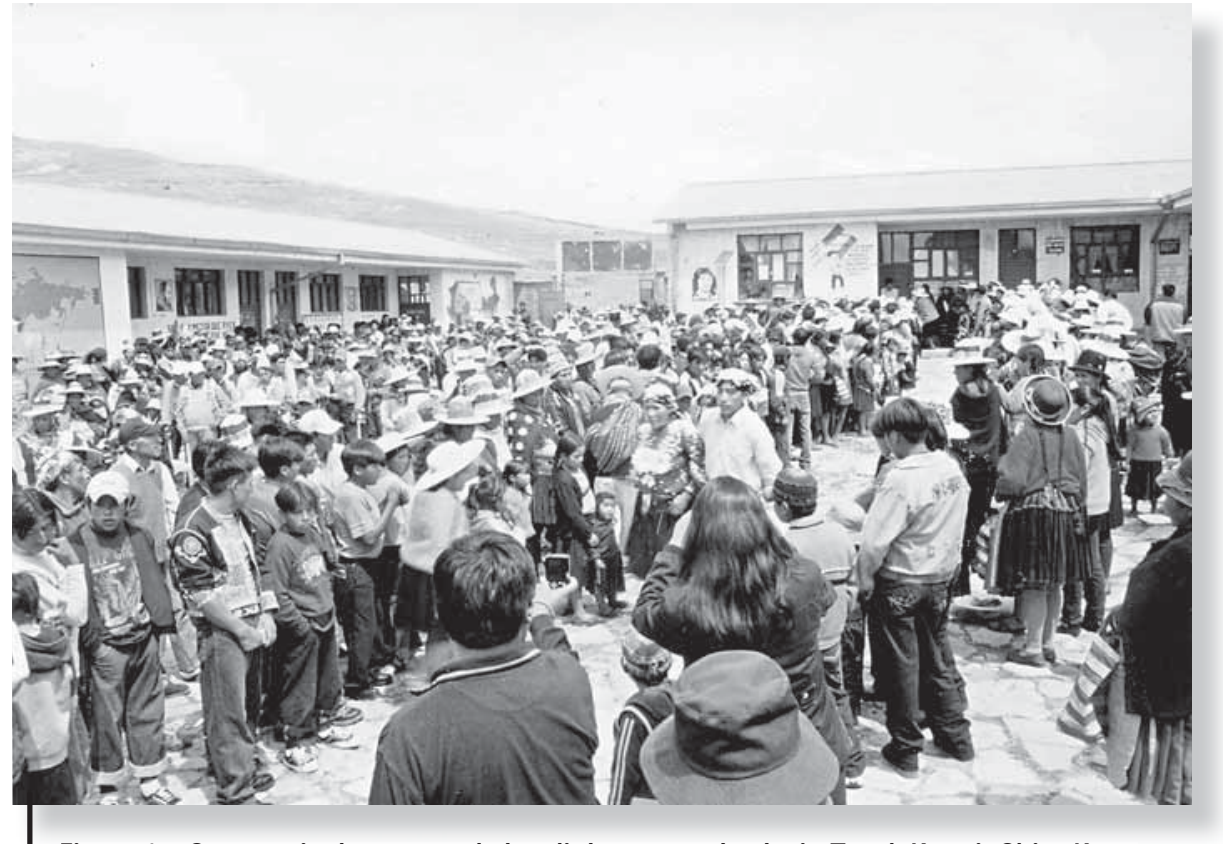

Figura 1 - Ceremonia de entrega de los diplomas en el colegio Tupak Katari, Chiro K'asa

(c) C. Le Gouill, 2010

iniciación del paso de la niñez a la edad adulta; mientras que para la segunda es una fuente de interés colectivo, con la formación de «profesionales» locales que en el futuro podrán ayudar a su desarrollo. Si esta articulación entre educación/saber y desarrollo puede ser encontrada en toda Bolivia, en el Norte Potosí se inscribe en un contexto regional marcado por la extrema pobreza. En efecto, de los trece municipios con los que la región contaba en 2005, doce tienen un índice de desarrollo de entre 0,340 y 0,460, lo que los coloca en el lugar 291 (Arampampa) y el lugar 326 (Colquechaca) de los 327 municipios registrados en el país. Solo el municipio minero de Llallagua, que es en su mayoría urbano, tiene una mejor ubicación (90). A pesar de que esta evaluación se basa en la visión «occidental» de desarrollo, esta pobreza contrasta con la riqueza en recursos minerales que ha distinguido históricamente esta región, la cual hizo posible la fortuna del «barón del estaño» Simón I. Patiño, quien fue considerado en la primera mitad del siglo XX como una de las personas más ricas del mundo. Además, debido a su situación de extrema pobreza, el Norte Potosí ha sido beneficiario, a partir de los años 1980, de varios proyectos de desarrollo por parte de diferentes O NG. El escaso impacto de dichos proyectos es demostrado por el hecho de que el Norte Potosí es considerado, aún a principios de los años 2000, como la región más pobre de Bolivia. Esta contradicción, junto con el sentimiento de injusticia que ha emergido, tanto en relación a la explotación de las tierras de los habitantes de esta región, como en relación con los resultados de los programas de desarrollo, han llevado a la creación de imágenes contradictorias acerca de esta noción por 
parte de la población indígena. Por un lado, existen varias críticas a los modelos económicos impulsados por las O N G y la industria minera. Por el otro, la presencia de varias O NG y partidos políticos ha conducido a la constitución de un «campo del desarrollo»-e incluso a constituir un «habitus desarrollista»- en el cual el desarrollo se encuentra al centro de los debates políticos y de las tensiones entre organizaciones sociales para la toma de los instrumentos tanto públicos como privados de implantaciones de los programas económicos (alcaldías, O NG...).

Este «habitus desarrollista» de las comunidades indígenas contradice las representaciones comunes acerca del mundo indígena, particularmente en el Estado Plurinacional de Bolivia, el cual reconoce el «vivir bien» indígena como «principio ético-moral» de la nación boliviana. Como lo mostraremos más adelante, el hecho de que el Estado defina los principios indígenas implica el riesgo de encerrar el mundo originario en un modelo romántico, propio a la construcción del «indio permitido», descrito por Charles Hale - a partir del concepto definido por Silvia Rivera Cusicanqui- como el ideal del «buen indio», integrado al Estado, moderno y cuyas reivindicaciones son compatibles con el proyecto estatal (Hale, 2004). En el Estado Plurinacional de Bolivia, la figura construida desde el Estado tiene, en efecto, el riesgo de reproducir la tutela estatal y de «patrimonializar» las culturas contra todo verdadero proceso de libre determinación de los pueblos indígenas. M ostraremos que, al contrario de lo que esa figura designa, la creciente integración de los pueblos indígenas a la sociedad circundante conduce a una hibridación de las prácticas «tradicionales»y «modernas» (Le Gouill, 2015) y a superposiciones de antiguas y nuevas formas organizativas de poder y gobernanza (Gros, 2010).

En una primera parte, analizaremos los conceptos de saber y de desarrollo en el mundo indígena nortepotosino. Luego describiremos los cambios que el crecimiento de la educación y los programas de desarrollo impulsados por las O NG han introducido en las representaciones colectivas acerca de estos conceptos. Analizaremos cómo dichos cambios han desembocado en la constitución del «habitus desarrollista» y han acarreado consecuencias tanto a nivel político como organizativo. Finalmente, concluiremos con una reflexión general sobre la lucha contra la pobreza en el Norte Potosí.

\section{1. «SABER» $Y$ «DESARRO LLO»EN EL MUNDO INDÍGENA}

El desarrollo ha sido generalmente asociado a «ideologías» (O livier de Sardan, 1995) que promueven los grandes modelos impulsados desde arriba y al «desarrollismo», definido como una «teología de progreso» (Arnold, 2008b) o una «religión moderna» basada en el «crecimiento económico» (Rist, 1996). Según dicha ideología, el desarrollo de los territorios indígenas podría provenir solo del exterior y darse únicamente bajo la tutela del Estado o de las organizaciones internacionales. Sobre esta base se construyeron varios modelos de desarrollo y de modernización del campo desde la reforma agraria de 1953 hasta el «desarrollo con identidad» promulgado por la cooperación internacional a partir de los años 1990 (Gros \& Foyer, 2010). A la inversa de esta dinámica, la capacidad de los pueblos indígenas a organizar sus propios 
modelos económicos según sus «visiones propias» fue reconocida en el Convenio 169 de la O rganización Internacional del Trabajo de 1989 y en la Declaración de los Derechos de los Pueblos Indígenas de las Naciones U nidas de 2007, los cuales son reconocidos como leyes por el actual Estado Plurinacional Boliviano.

\section{1. Pobreza y riqueza en las comunidades}

Fuera de toda visión «desarrollista», D enise Arnold (2008a) explica que la búsqueda del desarrollo es al origen mismo de los grandes imperios andinosy de las estructuras indígenas locales centradas en el uso de un máximo de pisos ecológicos. La autora propone así rearticular los «territorios religiosos» con los «territorios de desarrollo» y explica que «muchas de las prácticas que se ven como "religiosas" desde la antropología o la sociología, son en realidad prácticas productivas», lo que implica, según ella, la necesidad de «resacralizar las prácticas de desarrollo» y «defetichizar las prácticas religiosas» (Arnold, 2008b: 27-28).

Hasta ahora, varios ayllus del Norte Potosí tienen acceso a diferentes pisos ecológicos desde la puna hasta los valles, lo cual permitió históricamente la circulación y los intercambios de productos dentro de lo que O livia Harris describe como la «economía étnica» (H arris, 1987a: 10). Esta economía responde a normas y valores propios de las comunidades, ya sea tanto al nivel de la circulación y del acceso a la tierra, como de la producción, con un sistema de organización familiar y comunal del trabajo (ayni, mink'a)2. A pesar de que se construye un «ideal igualitario» dentro de las comunidades, las formas de repartición y de solidaridad ocultan relaciones de dominación que se amplían a medida que las comunidades se integran a la sociedad circundante. Estos fenómenos son testigo de la formación de nuevas élites rurales, ya sean terratenientes, comerciantes o transportistas - que son las tres categorías más importantes de la estructura económica comunal actual (Zalles Cueto, 2000)- o élites involucradas en nuevas actividades como el turismo o la monoproducción agrícola, como muestra el caso de la quinoa en otras regiones del país (O rmachea \& Ramirez, 2013).

A nivel simbólico, el desarrollo puede ser asociado, según Denise Y. Arnold, al «crecimiento» de las culturas dentro de varios ciclos de producción (Arnold, 2008a) y a sus superposiciones a los ciclos de las fiestas (Fernández Juárez, 1995). Como lo indica Peter Gose (2001), no se puede así separar la producción agrícola de los aspectos económicos, sociales (reciprocidades, intercambios, ayni, mink'a), culturales (rituales) e identitarios (étnico y de clase). La relación con las divinidades de los cerros y de manera general con la pachamama es central en las fases de producción y marca una relación de dependencia frente a la naturaleza, que necesita ofrendas constantes para otorgar su generosidad 0 - en el caso de que las ofrendas no sean suficientes- su sanción. Esa relación con la naturaleza condujo a la

2 Varios autores han descrito el sistema de organización de la producción agrícola, entre otros Gose, 2001. 
constitución de la figura del «nativo ecológico» (Ulloa, 2007) a nivel internacional, a pesar de que la relación de las comunidades andinas con la pachamama no siempre fue «armónica», sino más bien marcada por tensiones (Poupeau, 2011).

Esa relación «ontológica» con la «naturaleza» no impidió el desarrollo de procesos mercantiles dentro de la «economía étnica» de los ayllus del N orte Potosí. En efecto, la «economía étnica» no excluye la circulación de la moneda entre los ayllus ni el acceso a los mercados. Según O livia Harris, el dinero no es percibido en los ayllus como una amenaza, sino más bien, es asociado a la vida, a las divinidades del subsuelo, a la fertilidad de la mina y su circulación responde a un ciclo productivo de igual manera que todos los productos agrícolas (H arris, 1987b). Ya Tristan Platt había mostrado el papel de los ayllus del Norte Potosí dentro de la economía colonial y sus relaciones mercantiles con los centros mineros que permitieron a la región del Norte Potosí ser el «granero de Bolivia» a través de la constitución de un «modelo cacical de mercantilismo agrario». Este modelo permitió a los kurakas movilizar la fuerza de trabajo de las comunidades, bajo el sistema de reciprocidad tradicional, para obtener los excedentes económicos necesarios al pago del tributo y, así, mantener el «pacto de reciprocidad» con el Estado. De esta manera, el aislamiento económico de los ayllus a partir de la época republicana fue más la consecuencia de las políticas gubernamentales que de una falta de adaptación a la «economía étnica» de los ayllus a la economía de mercado (Platt, 1982).

\section{2. La educación comunitaria no formal}

Como toda sociedad campesina, los ayllus del Norte Potosí adquirieron muchos saberes acerca de la gestión de sus ciclos de producción, como también acerca de la manera de mantener relaciones con las divinidades y la naturaleza. Se puede decir que el saber indígena tradicional - relativo a los usos y costumbres, al territorio, a la relación sagrada con la naturaleza... - tiene como objetivo principal la reproducción del grupo social. Como lo escribe Gilles Rivière, la agricultura y la ganadería responden a una «cosmología» que asocia las evoluciones del clima a las turbulencias sociales, ya sean las relaciones entre los hombres mismos o entre los hombres y los dioses. El saber está, de esta manera, asociado a la interpretación y a la prevención. Es decir, a una «gestión de lo aleatorio» que debe permitir anticipar los eventos del futuro e interpretar las dificultades de los ciclos agrícolas (Rivière, 2002).

El saber se traduce en quechua como yachay y se expresa a partir de la raíz yatien aimara3. Dicho término "abarca no sólo la capacidad cognitiva del saber, sino, abarca también el campo de las habilidades del saber hacer algo y la adquisición de un hábito» (Pari, 2009). Las comunidades pueden poseer un saber de dos maneras. En la región en que fue realizada la investigación, una primera proviene de un don

3 El Jatun Ayllu Q hayana donde se hizo una parte de la investigación en el Norte Potosí se caracteriza por ser una región históricamente aimarahablante, a pesar de que el idioma quechua se desarrolló 
de la naturaleza recibido del rayo, que da a la persona capacidades especiales que le permitirán acceder al estatuto de yatiri («el que sabe», en aimara) después de un proceso de formación con otros especialistas. El yatiri tiene el poder de acceder al «mundo invisible» por su relación con los espíritus de los cerros y de las plantas, lo que le permite interpretar los mensajes y restablecer el equilibrio social y cósmico (pampachaña) (Rivière, 2002) a través de sus ofrendas y mesas (Fernández Juárez, 1995). O tra forma de saber está basada en la experiencia vivida a través de los cargos de autoridades (thaki, «camino» en aimara) dentro de la estructura comunal del poder. El thaki es el «servicio comunal obligatorio», que corresponde a

la secuencia de cargos y responsabilidades públicas por los que un determinado comunario va «caminando» en el correr de los años hasta llegar a su plenitud, con el máximo de reconocimiento y prestigio (Ticona \& Albo, 1997: 66).

Entrar en el thaki significa pasar de ser un individuo «irresponsable» a una persona «responsable» (Ticona \& Albo, 1997: 66). En el Norte Potosí esto sucede gracias al matrimonio, que permite a la pareja entrar plenamente en el thaki construyéndose como jaq'i (o runa, en quechua), es decir «persona entera» y miembro de la comunidad con derechos (acceso a la tierra) y obligaciones (thaki, trabajos colectivos). Si algunas autoridades acceden a un poder «chamánico» (Rivière, 2002), en la mayoría de los casos las autoridades se quedan bajo la influencia de los yatiris, a pesar de que deben realizar varios rituales y deben tener un conocimiento importante del territorio y de las familias del ayllu. La autoridad no tiene un verdadero poder, el cual recae en las asambleas comunitarias. Sin embargo, el sistema de cargo representa «la estructura social, ideológica y económica» del grupo y su identidad (Rivière, 1982).

Si bien el thaki significa que el saber está en las manos de las personas mayores, con experiencia, quienes pasaron los cargos los más importantes, los jóvenes no se quedan fuera de este proceso. Estos últimos conocen un proceso de formación constante a lo largo de la vida que llamaremos «educación comunitaria no formal», cuyos principales valores se quedan en el tema de la reproducción del grupo social. Como lo escribe Tiina Saaresranta,

la educación comunitaria busca satisfacer las necesidades comunitarias e individuales para garantizar la subsistencia familiar y comunitaria, transmitir los conocimientos sobre los trabajos productivos, las reglas de convivencia y organización, las costumbres y tradiciones que son importantes según cada contexto para ser trasmitidos a las generaciones jóvenes (Saaresranta, 2011).

Según la autora, la educación comunitaria indígena no formal define el proceso de formación de la persona para llegar a ser un miembro entero de la sociedad. Ese constante proceso de formación puede traducirse en quechua como runayay, lo que significa llegar a ser un verdadero ser humano, es decir una persona que

a partir de los años 1980 hasta tal punto de ser hoy día el idioma «oficial» de las escuelas bilingues. Así, en tres generaciones el Jatun Ayllu Q hayana podría pasar de un lugar aimarahablante a una zona quechuahablante. 
tiene la formación en valores, así como la capacidad y la sabiduría de usar de manera adecuada los conocimientos adquiridos (Saaresranta, 2011).

A través de la educación, al igual que a través del thaki y del matrimonio, la persona llega a constituirse como jaq'i o runa4.

En conclusión, se puede decir que el saber está asociado al mundo interno de las comunidades, ya sea por la relación que este mantiene con las divinidades, con la naturaleza y el territorio, y con la organización comunitaria. Es un elemento central en la construcción de la identidad del grupo y en la reproducción de su economía, y tiene el objetivo de mantener el equilibrio social y la armonía con la «naturaleza» con fines productivos. No obstante, la visión propia que los ayllus del Norte Potosí tienen del desarrollo entra en competencia con otras formas del saber, que se desarrollan a través de las escuelas y las O NG, como veremos a continuación.

\section{DINÁMICAS INDIVIDU ALES Y COLECTIVAS DEL SABER Y DEL DESARRO LLO}

La investigación realizada en el Norte Potosí mostró que la lucha de las organizaciones sociales por el control del mundo rural era inseparable de las formaciones de líderes para encabezar los proyectos de desarrollo y las luchas políticas (Le Gouill, 2014). Si el «líder» puede ser una persona mayor por sus conocimientos adquiridos durante el thaki, nuevos líderes han emergido a partir de nuevas formas de saberes adquiridos a través de otros procesos de formación, fuera de la educación comunitaria indígena (fig. 2): escuelas, centros de formación, universidades...

Los líderes encontrados durante la investigación beneficiaron así de fuertes «capitales económicos» dentro de sus familias5 0 de fuertes «capitales sociales» dentro de organizaciones sociales que les permitieron acceder a estos nuevos tipos de conocimiento. La escolarización depende también de la estrategia familiar de reproducción social familiar. Así, los niños deben acompañar a sus padres durante las actividades agrícolas - ya sea la vigilancia de las ovejas para los más pequeños, hasta las actividades propiamente agrícolas para los mayores- y solo es la reproducción de la fuerza de trabajo familiar que permite al hijo salir del hogar al alcanzar la mayoría de edad para continuar sus estudios o trabajar de manera permanente en las ciudades (en el caso del Norte Potosí, generalmente como albañil en Cochabamba y anteriormente como minero en Llallagua). De esta manera, la escolaridad del último hijo es, en la mayoría de los casos, sacrificada al beneficio del acompañamiento de sus padres hasta su muerte. La escolarización es también un fenómeno sexuado por el hecho de que las hijas juegan un papel importante en actividades agrícolas, y, a

4 Gilles Rivière indica que en el caso de Sabaya (O ruro) casarse lleva a «hacerse adulto» (jaqichaña en aimara) pero que solo el matrimonio no permite a la persona ser jaq' $i$ si no ha pasado cargos dentro del thaki (comentarios personales), lo que muestra una misma relación entre matrimonio y saber.

5 La investigación mostró que las familias en proceso de ascenso social son las que más invierten en la educación de sus hijos. 


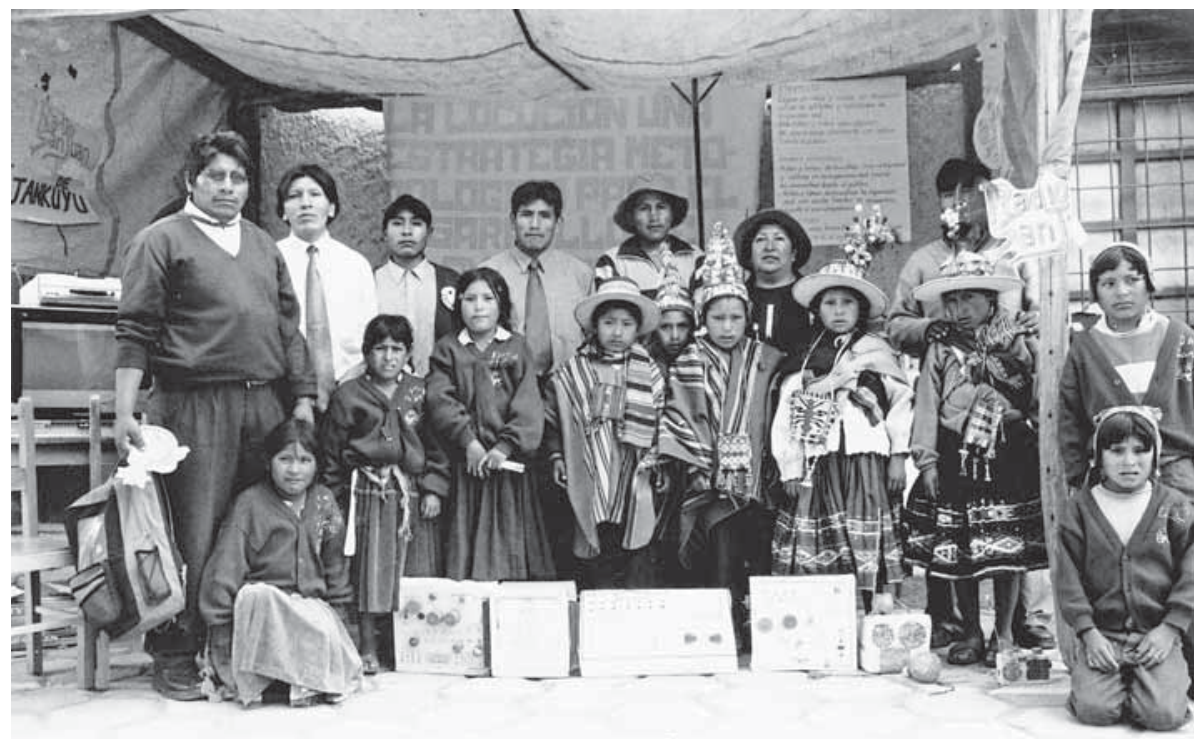

Figura 2 - Taller de iniciación a la radio para los jóvenes

(c) C. Le Gouill, Sacaca, 2009

diferencia de sus hermanos, también en actividades domésticas y en el cuidado de los niños más jóvenes de la familia. Esta división sexual del trabajo familiar conduce a las mujeres a tener un menor acceso a la escuela.

\section{1. El desarrollo de la educación formal}

De manera paralela a la educación comunitaria no formal, se ha desarrollado poco a poco en el mundo rural la educación formal del Estado. Si desde la colonia española existían «escuelas de caciques» para formar los intermediarios entre la Corona y los territorios indígenas, los proyectos educativos más amplios se impulsan solo a inicios del siglo XX, con la visión de «desindianizar la sociedad» (Martínez, 1998). Todavía en la primera mitad del siglo XX, nacieron otros proyectos educativos no formales bajo el impulso de mestizos influenciados por el marxismo. La «escuela-ayllu» de Warisata es la más importante de este tipo y, a pesar de basarse en una visión indigenista, se caracteriza por promover un fuerte proyecto productivo y desarrollista que proponía una «educación integral»; es decir, una continuidad académica desde las actividades de los niños hasta la formación de técnicos profesionales y profesores indígenas (Pérez, 1992). Esta escuela influenció varios otros proyectos, algunos de los cuales se encontraban en la región del Norte Potosí6. La investigación mostró, a partir de los años 1940, la

6 Según varios testimonios, sería por ejemplo el caso de la escuela de Irupata (ayllu Chayantaka). 
creación de varias escuelas «pitanzas» en las cuales se pagaban a los profesores en productos agrícolas del campo. Si bien todas estas escuelas no tenían un aspecto político como la de Warisata, estas son prueba de los intereses de los comunarios, quienes participaron en su creación, ofreciendo terrenos y mano de obra para su construcción, además de pagar directamente a los profesores.

La primera política educativa llegó en 1955, después de la Revolución del Movimiento Nacionalista Revolucionario (MNR), a través de una reforma educativa, que reconocía la educación como universal, gratuita y obligatoria hasta los 14 años. Varias escuelas fueron construidas a partir de ese momento en el Norte Potosí. En ellas, los profesores fueron, en su gran mayoría, hijos de terratenientes que usabann la educación para controlar los movimientos campesinos-indígenas en el campo. Nacida como proyecto político de transformación de la estructura del país, esta reforma se convirtió poco a poco en una «ideología de movilidad social» defendiendo la creencia que la educación podría influenciar el bienestar de las personas (Zalles Cuto, 2000) e incorporando así una primera ideología individualista en las escuelas.

En el Norte Potosí, se tuvo que esperar hasta los años 1970 para que una nueva generación de profesores con una visión más política de cambio social tomaran acceso a los cargos. Colegiose internados se desarrollaron de la misma manera en los «pueblos de comunarios»7, a veces bajo la influencia de la Iglesia Católica; y, en las zonas mineras, bajo la influencia de sindicatos y partidos políticos obreros, lo cual permite a la población campesina-indígena beneficiar de un marco más propicio para construir un discurso político. Ese proceso se acelera con el impulso de las ONG para constituir una educación no formal con los Centros de Educación Técnica, Humanística y Agrícola (CETHA8) y con varios talleres de formaciones en temas agrícolas y de desarrollo a partir de la sequía de 1983. Además, se constituyeron centros de formación impulsados por partidos políticos. El M ovimiento de la Izquierda Revolucionaria (MIR) creó en 1976 su propio centro de formación de líderes, el Instituto Politécnico Tomas Katari (IPTK), en Ocuri, con un fuerte enfoque desarrollista. El objetivo del IPTK era la formación técnica (agronomía, salud, administración pública, mecánica), además de una importante formación político sindical, para formar líderes profesionales comprometidos con ideas de izquierda para impulsar un sindicalismo independiente. A partir de la sequía de 1983, el Norte Potosí recibió un gran apoyo internacional por parte de varias O NG por ser declarado «zona roja», debido a su extrema pobreza. La Federación Sindical Campesina buscó, a partir de este momento, desempeñar un papel más importante que el de simple receptor de la ayuda. Apoyándose en su red y sus diferentes niveles de organización, llegó a impulsar sus propios proyectos

7 Estos pueblos nacieron en muchos casos con la construcción de caminos y gracias a la dinámica de los propios comunarios. Se convirtieron en pequeñas zonas urbanas de contra-poder frente a las antiguos «pueblos coloniales» (controlados por las élites de los vecinos), con sus propias escuelas, oficinas, tiendas... (Fernández 0 sco, 2004).

8 LOS CETHA tienen como función la formación de los adultos y de las personas que no pudieron integrar las escuelas formales. 
de desarrollo y a desempeñar el papel de articulación entre la ayuda internacional y las comunidades para controlar y orientar dicha ayuda9. Se firmaron así varios convenios con O N G y muchos campesinos recibieron capacitación en agronomía, administración y evaluación de proyectos (Rivera, 1992; Le Gouill, 2014). En

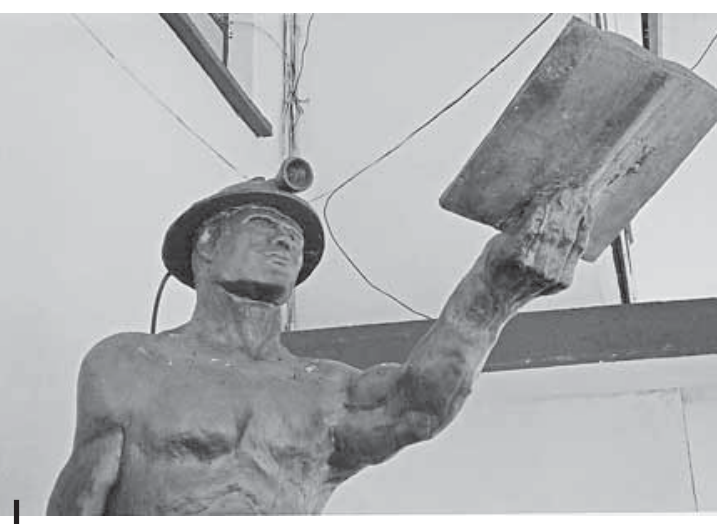

Figura 3 - De los mineros a los estudiantes

Estatua en la entrada de la Universidad Nacional Siglo $X X$ de Llallagua

(c) C. Le Gouill, Llallagua, 2010 competencia con ese proceso político, en los años 1980, el movimiento katarista nortepotosino constituye su propio centro de formación, el Centro Marka, para formar líderes en Ciencias Sociales con el objetivo de impulsar la «reconstitución de los ayllus», además de crear una red de ONG kataristas involucradas en el desarrollo de la región. En 1985, es importante notar además la creación, por parte de la Federación Sindical de los Trabajadores Mineros de Bolivia, de la Universidad Nacional «Siglo XX», con el objetivo de formar «profesionales comprometidos» en la región para favorecer el cambio social y el desarrollo del Norte Potosí (fig. 3). Como lo indica el Estatuto O rgánico de esa universidad, su objetivo es desarrollar una práctica de aprendizaje integral que comprenda el conocimiento teórico, experimental y manual del proceso productivo, destinado a disminuir la distancia entre el trabajo intelectual y manual, con el propósito de lograr un profesional capaz de responder a los intereses colectivos del pueblo (UNSXX, 2000: 4).

Su trámite no es así tan lejano del proyecto «integral» de la escuela-ayllu de Warisata con un enfoque productivista de mejoramiento de las condiciones de vida en la región.

Estas formaciones de «profesionales» desempeñan un papel importante a partir de la Ley de Participación Popular de 1994, la cual condujo a un proceso de municipalización del país basada en la democracia participativa. Las organizaciones campesino-indígenas empezaron a conquistar espacios para impulsar sus propios proyectos de desarrollo dentro de los Distritos Municipales Indígenas (DMI) y luego, tras sus primeras victorias electorales en la región en 1999, en el seno mismo de las alcaldías. Esta conquista de nuevos espacios políticos ofrecieron a los líderes-profesionales nuevos espacios para expresar sus saberes acerca del desarrollo y del mundo exterior a las comunidades, espacios en los cuales los «saberes tradicionales» de los ancianos no tenían tanta legitimidad.

Del mismo modo que el antropólogo francés Jean-Pierre Olivier de Sardan, podemos ver en el Norte Potosí el nacimiento de un «campo de desarrollo»

9 Entrevista con Félix Vásquez (diciembre de 2009), dirigente histórico del sindicato campesino en el Norte Potosí y uno de los principales propulsores de ese proceso de desarrollo. 
regional, con sus instituciones, lenguajes específicos, ideologías, capacitaciones y símbolos (Olivier de Sardan, 1995). Cada organización social busca así tejer su propia red institucional apoyándose sobre los organismos de desarrollo para conquistar el poder regional y proponer sus propios proyectos de desarrollo. Estas organizaciones e instituciones entran así en un gran proceso competitivo en la «carrera del desarrollo» llevada en el Norte Potosí, del cual nace el «habitus desarrollista» que definiremos más adelante.

\section{2. La educación como proyecto colectivo}

Como lo decía un comunario refiriéndose al cambio social que permitió a las organizaciones indígenas conquistar el poder municipal: «Ahora no tenemos miedo porque tenemos profesionales»10. El «profesional» se traduce así también como el «líder» que orienta a la comunidad y que permite competir con el grupo dominante de los terratenientes mestizos. La visión tradicional del poder mestizo asociado a la tierra fue así reemplazada por el poder del saber. Las comunidades indígenas ya no tienen «miedo» porque tienen «líderes» para orientarlas pero también porque son aptas para conquistar el poder ya que ellas también «saben». El acceso de los comunarios a los lugares de producción del saber de la sociedad dominante - al mismo tiempo que la reforma agraria disminuyó la articulación poder/tierra- desplazó la visión del saber interno de las comunidades hasta un saber orientado hacia afuera. Este nuevo saber conduce a nuevas formas de relación con el mundo exterior, pero que reproducen la misma articulación entre saber y poder que existía en las comunidades, es decir que «el que sabe» tiene un estatuto a parte dentro de la comunidad. Sin embargo, a diferencia del «saber tradicional» este nuevo saber no conduce a un estatuto oficializado, como el de «autoridad» 0 «yatiri», sino más bien a un estatuto informal de líder, pero que confiere toda legitimidad para orientar los debates durante las asambleas comunitarias11. En este sentido, es interesante notar lo que describe Guillermo Salas para el caso peruano. Revela que los apus (divinidad de los cerros'2) - quienes tradicionalmente estuvieron asociados a los terratenientes- desempeñan después de la reforma agraria peruana de 1969 un papel ambiguo representando a la vez la autenticidad de la indianidad y el poder de los estatutos profesionales (abogados, militares...) (Salas, 2012), lo que muestra un cambio de paradigma dentro de la relación de poder con la sociedad dominante, pasando de una relación tierra/ poder a una relación saber/poder.

10 Entrevista con Benedicto Colque, Chiro K'asa, abril de 2011.

11 Además hemos mostrado que el líder podría tener un estatuto más importante que la autoridad por el hecho de que la autoridad no tiene tradicionalmente un real poder dentro de la asamblea para orientarla, sobre todo cuando se trata de temas específicos que necesitan saberes diferentes a los «saberes tradicionales» (Le Gouill, 2015).

12 Los apus son llamados en otras regiones wamanis, achachilas como también mallkus. 
No es por casualidad que la ceremonia que describimos en la introducción sea calificada como «una de las tres fiestas más importantes del ayllu», ya que simboliza el resultado concreto de la inversión comunal en la educación. Esa inversión se encuentra tanto en el papel de las comunidades mismas para la construcción de las primeras escuelas, como en la lucha para la conquista del control de las O NG y de los diferentes procesos de capacitación. 0 tro ejemplo es el hecho de que para entrar en el IPTK, los jóvenes tenían que conseguir una carta oficial de permiso por parte de su comunidad, lo que muestra una dinámica comunitaria y «orgánica» en el proceso de formación. Como en toda Bolivia, las comunidades tienen también un control del aparato educativo a través del cargo de «junta escolar» cuya función es la articulación de los profesores y los comunarios. Sin embargo, esa inversión no puede ser rentable si el bachiller no continúa sus estudios en la universidad o por medio de formaciones técnicas que le permitan regresar a las comunidades con proyectos de desarrollo o nuevos conocimientos para impulsar políticas desarrollistas. Es en este sentido que las redes sociales construidas por las organizaciones sociales dentro del «campo de desarrollo» (con las O NG, institutos de formación) desempeñan un papel fundamental para permitir la continuidad de la escolarización de los jóvenes. Así, como lo escribe Lange, «la educación para todos es de alguna manera concebida como la educación de algunos al beneficio de todos» (Lange, 2003: 160, citada por Lewandowski, 2007) y que podemos entender la dimensión colectiva de las escuelas en el mundo rural.

Más allá de las estrategias familiares, la escolarización depende de la red de parentesco más amplia, del compadrazgo y de los vínculos de la familia con organizaciones sociales y políticas. En efecto, es en este contexto que se orienta la trayectoria escolar y la elección de la vía escolar formal o no formal, gracias a las posibilidades de becas y de financiamiento por el compadre13. El líder se encuentra así en situación de deuda frente al grupo o a la persona que le orientó en su trayectoria. La deuda adquirida durante la escolaridad debe ser restituida al final de la escolarización gracias al compromiso del nuevo «profesional» en apoyar de manera económica, política o técnica a su familia, a su organización o a su compadre, lo que conduce al mantenimiento de los lazos familiares y clientelares, según el «individualismo de grupo» propio del mundo aimarahablante (Albó, 1977). La persona educada se encuentra doblemente dependiente de la red que la apoyó en sus estudios. Por un lado, porque fue socializado en el discurso político; por otro, porque debe fidelidad a cambio del reembolso de la deuda. De otra manera, será percibido como traidor o como una persona quien buscó sus «intereses personales». El ascenso social de una persona y la riqueza adquirida por su trabajo con ONG o en cargos de administración podrán tolerarse por la comunidad solo si el «profesional» se compromete con la comunidad como una

13 La investigación en el Norte Potosí mostró en efecto cómo las orientaciones ideológicas de los padres - entre sindicalismo campesino y organización del ayllu - influenciaron los lugares de formaciones de los jóvenes (IPTK o Centro M arka) y las posibilidades de acceso a cargos dentro de ONG o en los municipios. 
forma de repartición propia al mito del «igualitarismo comunal», es decir a sus formas de reciprocidad y repartición de la riqueza (Le Gouill, 2015). Sin embargo, si estos nuevos saberes son integrados a las normas y a los valores comunales, no impiden que puedan existir «un grupo de valores competitivos, complementarios o incluso contradictorios» (Canessa, 2006: 106) como lo veremos ahora.

\section{3. La constitución de un «habitus desarrollista»}

Si el desarrollo está íntimamente articulado al territorio, a la religión y al saber en el mundo indígena, ¿en qué sentido entonces podemos hablar de un «habitus desarrollista»? Este habitus encuentra su origen en la creación del desarrollo como «campo». Es dentro de este campo que se constituye un «habitus desarrollista» que podemos definir, a partir del concepto de «habitus» de Pierre Bourdieu (1994), como la generación de prácticas y representaciones conscientes y subconscientes acerca del «desarrollo». Ellas provienen tanto de las prácticas tradicionales acerca del desarrollo de los ayllus - o sea de sus prácticas de producción (prácticas de reciprocidad, ritualidad...) definidas de manera esquematizada como el «vivir bien»- como de la «creencia en el progreso» introducida por los agentes de desarrollo, adquirida a través de socializaciones (primaria, secundaria, profesional) en el seno del «campo de desarrollo». Ese «habitus» encuentra en los ayllus del Norte Potosí un terreno particularmente fértil a su implantación, debido, por una parte, a la visión tradicional de las comunidades sobre la producción agrícola y, por otra, a los procesos históricos de integración a los mercados y de socialización hacia la ideología «desarrollista» de izquierda, que han sido marcados por la presencia cercana de los centros mineros. No obstante, este «habitus» no significa que haya desaparecido toda forma de «armonía con la naturaleza» o toda «reciprocidad» en esas comunidades. Significa que la «creencia occidental en el progreso» penetró en las comunidades nortepotosinas sin que necesariamente hayan desaparecido otras visiones de los intercambios de bienes materiales y simbólicos, lo que conduce a confrontaciones de interpretaciones, así como a formas híbridas de procesos de desarrollo. Ese habitus significa más bien que las visiones del desarrollo cohabitan en las comunidades y que una u otra puede activarse y reivindicarse según los momentos y las oportunidades políticas que se presentan. Cada universo está controlado por distintos actores en las comunidades - autoridades tradicionales y líderes-profesionales- y cada actor desempeña un papel complementario para el «desarrollo» de la comunidad, ya sea en su forma tradicional o desarrollista. Así, si la ideología del «vivir mejor» penetró en las comunidades, eso no significa que ellas no pueden reivindicar el «vivir bien» para enfrentarse a otros proyectos y visiones que parezcan contrarios a la reproducción armónica del grupo social. Al contrario de todo esencialismo, podemos definir el tema del «desarrollo», tal como lo hemos hecho con otros temas como los «usos y costumbres» (Le Gouill, 2015), como un «campo de conflictos» en el cual se oponen diferentes visiones, actores y representaciones. Esa dinámica va así en contra de todo proyecto de desarrollo impulsado «desde arriba», ya sea en su forma tanto extractivista como etnodesarrollista (fig. 4). 


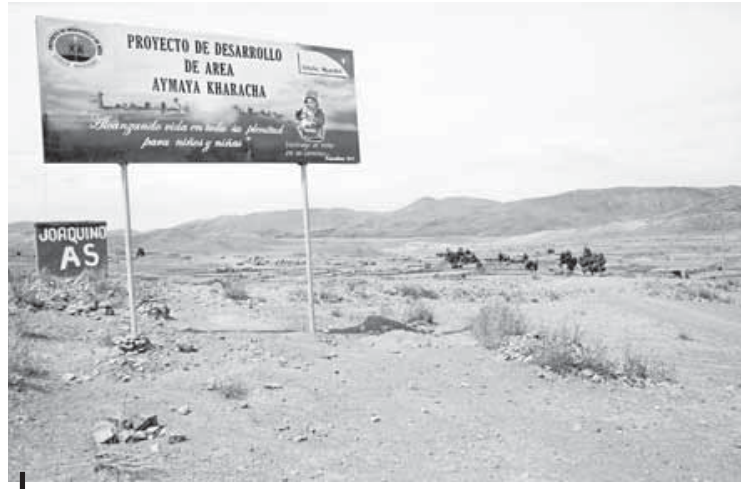

Figura 4 - Proyecto de desarrollo en el Norte Potosí

En la entrada de cada pueblo se pueden ver letreros de los programas de desarrollo y de sus ONG

(c) C. Le Gouill, Uncia, 2009
En el Norte Potosí, el discurso «desarrollista» encontró un terreno fértil por la influencia ideológica de los movimientos obreros y partidos políticos de izquierda, los cuales sostuvieron los méritos del crecimiento de las fuerzas productivasydel modelo industrial. El tema minero es particularmente representativo de esa dinámica, en el cual prevalece el mito «eldoradista» sobre la «maldición de la abundancia» que se encuentra en otras partes de América Latina (Svampa, 2012). Varios estudios han mostrado que las comunidades indígenas en Bolivia se caracterizan por una aceptación de la explotación minera (Madrid, 2014), más allá de «la interpretación panteísta de la pachamama» para favorecer un uso más pragmático de los recursos naturales en sus territorios (Portugal, 2011), según el mito «eldoradista» común en Bolivia descrito por René Zavaleta de una esperanza mística basada en el descubrimiento de bienes naturales para producir excedentes materiales como por «magia» (Svampa, 2012). Fue por ejemplo el caso de Mallku Khota, en el que los comunarios no pelearon contra la explotación minera, sino más bien por un nuevo modelo de empresa minera comunitaria14. El tema minero muestra así el papel central del derecho a la «consulta previa libre y de buena fe» y a la libre determinación para que los pueblos indígenas lleguen a impulsar sus propios modelos de desarrollo, según sus visiones propias, fuera de todo esencialismo romántico o proyecto neoliberal destructor. Como lo escribe Christian Gros,

no es pensable, ni factible promover un «desarrollo con identidad» en una sociedad que se reconoce como multicultural sin aceptar y promover un verdadero nivel de autonomía para pueblos hasta hoy mantenidos en una posición subordinada (Gros, 2010: 371).

14 Emilio Madrid (Madrid, 2014) mostró que existe muy pocos casos de luchas indígenas en contra de toda explotación minera, a pesar de algunos casos como son los territorios que conocieron una fuerte contaminación ecológica de largo plazo (caso de los habitantes reunidos en el Comité de Defensa de la Cuenca Desaguadero Lagos Popoo Uru-U ru-Coridup) o de los territorios que privilegiaron otras fuentes de desarrollo comunitario como es el caso de Challapata (quinoa) o de la Chiquitania (bosque). 


\section{CONCLUSIÓ N: ¿LA EDUCACIÓN Y EL DESARRO LLO AL SERVICIO DE LA LUCHA CONTRA LA PO BREZA?}

La relación de los ayllus del Norte Potosí con la naturaleza se expresa tanto en las prácticas productivas como en el conjunto de las prácticas sociales. Esas representaciones llevaron a los pueblos indígenas en América Latina a una estrecha relación con los movimientos ambientales y encontraron en las representaciones occidentales del «nativo ecológico» un espacio para reivindicar sus derechos (Ulloa, 2007). Sin embargo, si esta construcción esencialista de la identidad indígena relacionada íntimamente con el «indio permitido» ha dado resultados políticos, la situación económica de los pueblos no beneficia de esa nueva situación (Gros, 2010).

El «habitus desarrollista» que hemos descrito no significa que ya no existan representaciones del «vivir bien» que puedan ser movilizadas por los ayllus del Norte Potosí. Más bien queremosindicar que estas reivindicaciones no pueden ser encerradas en una visión simple de la «indigeneidad», como lo describe Andrew Canessa (2006), fuera de sus realidades y aspiraciones propias15. Así, la lucha de las organizaciones del Norte Potosí para tomar el control de las ONG y de los proyectos de desarrollo se puede entender como una estrategia de toma del control del desarrollo mismo en contra de los «intermediarios» mestizos, así como una conquista de su autonomía. En efecto, los principales problemas relativos al desarrollo de las comunidades no provienen de las diferencias que, dentro de las comunidades, existen entre lo «tradicional» y lo «moderno» sino - tal vez ante todo- de las presiones exteriores (Estado, empresas, O NG ...) que impiden el verdadero debate interno en las comunidades alrededor de su futuro. Así, si las luchas por el «reconocimiento» de los movimientos campesino-indígenas necesitaban una cierta idealización de sus prácticas organizativas y culturales - es decir un «esencialismo» (Sierra, 1997) — ahora la lucha por la «repartición» y el desarrollo propio necesitan otra lógica discursiva.

La cuestión central en este caso es ¿qué cambian estos nuevos actores indígenas profesionales del desarrollo? ¿Buscan implementar los mismos proyectos, 0 impulsar un verdadero debate en las comunidades sobre su visión del desarrollo? Responder a esa pregunta necesitaría realizar una fina etnografia de los procesos discursivos dentro del «campo del desarrollo» nortepotosino que no realizamos en profundidad. Sin embargo, en conclusión, sin tener la pretensión de definir aquí una receta de lucha contra la pobreza, podemos decir que si está claro que el tema del desarrollo es central en los discursos de las comunidades, organizaciones sociales y líderes, los caminos para llegar a la lucha contra la pobreza no están todavía bien definidos.

15 Es interesante notar que durante el conflicto del TIPNIS, fue justamente el proyecto del gobierno encerar a los pueblos indígenas en la imagen del «buen salvaje» declarando la intangibilidad del territorio, como si estos pueblos no tenían capacidades para construir sus propias formas de desarrollo y orientarlas afuera de los paradigmas dominantes, que sean la visión romántica de relación armónica con la naturaleza o del desarrollismo estatal. 
En efecto, el «campo de desarrollo» está atravesado por varios discursose ideologías contradictorios por parte de las organizaciones sociales y O NG, alrededor del tema de la lucha contra la pobreza. Por ejemplo, las organizaciones campesinasindígenas actúan como «grupos de intereses» que buscan el desarrollo por vías diferentes - que sea la «reconstitución de los ayllus» y de los pisos ecológicos para la FAOINP, o la ayuda a la agricultura parcelaria para el sindicato campesinoy únicamente por sus bases sociales, excluyendo en muchos casos los otros sectores sociales no afiliados según el «faccionalismo aimara» descrito por Xavier Albó (1977). Este «dualismo organizacional» entre ayllus y sindicatos - en el cual estuvieron implicadas sus redes propias de ONG - determinó la imposibilidad de construir una política común de desarrollo regional, y llegó a bloquear toda dinámica regional, ya sea de la red ínterinstitucional del Norte Potosí que reúne varias $O N G$, o de los proyectos de la mancomunidad del Norte Potosí a nivel municipal. El problema se reproduce en el contexto de la educación por el hecho de que el «profesional» debe responder, ante todo, a su grupo familiar o a su organización, lo cual conduce al mantenimiento de los proyectos corporativos y de los vínculos clientelares e impide la «buena gobernanza» de la lucha contra la pobreza. Sin embargo, a pesar de los conflictos ideológicos, la investigación mostró varias alianzas entre organizaciones sociales para poner fin a los conflictos que bloquearon la llegada de O NG. Se realizó además una alianza entre las dos organizaciones de jóvenes - la del ayllu y la del sindicato- alrededor de una identidad común «juvenil» y de la imagen del «joven líder» como actor central del proceso de cambio y del desarrollo nacional. Así, si el desarrollo es objeto de luchas, puede ser también el factor principal de unidad.

En este sentido, no se puede pensar la lucha contra la pobreza solo a partir de dinámicas individuales como lo hace el Banco Mundial (Lewandowski, 2007), pero más bien se deben entender las dinámicas colectivas - orgánicas a las organizacionessocialesy comunitarias dentro de lascomunidades- de losprocesos educativos y políticos. Además, se deben tomar en cuenta las nuevas posibilidades de ascenso social que vive ahora la nueva generación de «profesionales». Desde la llegada de Evo Morales a la presidencia, estos jóvenes ven oportunidades casi ilimitadas de conquista de cargos hasta los más altos niveles de la estructura estatal. Este contexto favorece así las tensiones entre estrategias colectivas e individuales y podría acelerar el proceso de migración de los «profesionales indígenas» hacia las ciudades, si las políticas públicas no se orientan a favorecer el desarrollo local impulsado directamente desde las comunidades, es decir a partir de sus visiones propias del desarrollo reconocidas por el Estado Plurinacional boliviano. 


\section{Referencias citadas}

ALBÓ , X., 1977 - La paradoja aymara: solidaridad y faccionalismo, 54 pp.; La Paz: Centro de Investigación y Promoción del Campesinado (CIPCA).

ARNOLD, D., 2008a - Religión y desarrollo en los Andes. Deconstrucción intercultural de una relación difícil, 186 pp.; La Paz: Instituto Superior Ecuménico Andino de Teología (ISEAT).

ARN O LD, D., 2008b - Entre los muertos, los diablos y el desarrollo en los Andes, 198 pp.; La Paz: Instituto Superior Ecuménico Andino de Teología (ISEAT).

BO URDIEU, P., 1994 - Raisons Pratiques. Sur la théorie de l'action, 251 pp.; París: Seuil.

CANESSA, A., 2006 - Minas, mote y muñecas. Identidades e indigeneidades en Larecaja, 217 pp.; La Paz: Mama Huaco.

FERNÁNDEZ JUÁREZ, G., 1995 - El banquete aymara. Mesas y yatiris, 570 pp.; La Paz: HISBO L.

FERNÁNDEZ OSCO, M., 2004 - La ley del ayllu. Jach'a justicia y jisk'a justicia (justicia mayor y justicia menor) en comunidades aymaras, 364 pp.; La Paz: Programa de Investigación Estratégica en Bolivia (PIEB).

GOSE, P., 2001 - Aguas mortíferas y cerros hambrientos. Rito agrario y formación de clases en un pueblo andino, 315 pp.; La Paz: Mama Huaco.

GROS, C., 2010 - Conclusiones generales. In: ¿Desarrollo con identidad? Gobernanza económica indígena. Siete estudios de casos (C. Gros \& J. Foyer, eds.): 359-389; Lima: Institut Français d'Études Andines (IFEA), Facultad Latinoamericana de Ciencias Sociales (FLACSO), Centro de Estudios Mexicanos y Centroamericanos (CEMCA).

GROS, C. \& FOYER, J. (eds.), 2010 - ¿Desarrollo con identidad? Gobernanza económica indígena. Siete estudios de casos, 393 pp.; Lima: Institut Français d'Études Andines (IFEA), Facultad Latinoamericana de Ciencias Sociales (FLACSO ), Centro de Estudios Mexicanos y Centroamericanos (CEM CA).

HALE, C., 2004 - Rethinking Indigenous Politics in the Era of the 'Indio Permitido'. North American Congress on Latin America (NACLA) Report on the Americas, 38 (2): 16-21.

HARRIS, O., 1987a - Economía étnica, 114 pp.; La Paz: HISBOL.

HARRIS, O., 1987b - Phaxsima y colqe: Significados del dinero en el Norte de Potosí. In: La participación indígena en los mercados surandinos (O. Harris, B. Larson \& E. Tendeter, eds): 235-280; La Paz: CERES.

LE GO UILL, C., 2014 - La otra cara del katarismo: la experiencia katarista de los ayllus del Norte Potosí. Tinkazos, 17 (35): 95-113.

LE GOUILL, C., 2015 - Les savoirs du poncho et de la cravate. Formations politiques et émergence des leaders indigènes en Bolivie. Cahiers de la recherche sur l'éducation et les savoirs (CRES), 14: 165-186.

LEW AN DO W SKI, S., 2007 - La scolarisation, moyen de lutte contre la pauvreté ? Cahiers de la recherche sur l'éducation et les savoirs (CRES), 6: 301-321.

MADRID LARA, E., 2014 - Conflictos socioambientales en la minería: límites y realidades de su gestión. In : La veta del conflicto. O cho miradas sobre conflictividad minera en Bolivia (2010-2014) (Fundación U NIR ed): 157-172; La Paz: Fundación U NIR.

MARTINEZ, F., 1998 - La peur blanche : un moteur de la politique éducative libérale en Bolivie (1899-1920). Bulletin de l'Institut Français d'Études Andines (IFEA), 27 (2): 265-283. 
OLIVIER DE SARDAN, J.-P., 1995 - Anthropologie et développement. Essai en socioanthropologie du changement social, 221 pp.; París: Association euro-africaine pour I'anthropologie du changement social et du développement, Karthala.

ORMACHEA, E. \& RAM ÍREZ, N., 2013 - Propriedad colectiva de la tierra y producción agrícola capitalista. El caso de la quinoa en el altiplano sur de Bolivia, 208 pp.; La Paz: Centro de Estudios para el Desarrollo Laboral y Agrario (CEDLA).

PARI, A., 2009 - Epistemología del conocimiento científico andino: yachaymanta yachay. El vuelo de la Luciérnaga 2. Revista semestral para el diálogo entre personas de pueblos y nacionalidades diferentes, 2: 46-67.

PEREZ, E., 1992 - Warisata: La escuela-ayllu, 349 pp.; La Paz: Centro de Estudios de la Realidad Económica y Social (CERES), HISBOL.

PLATT, T., 1982 - Le rôle de l'ayllu dans la reproduction du système marchand simple dans le Nord Potosi. In: De l'empreinte à l'emprise. Identités andines et logiques paysannes (L. Briggs, ed.): 30-89; París: Presses U niversitaires de France (PU F).

PORTUGAL, P., 2011 - Visión posmoderna y visión andina del desarrollo. In: El desarrollo en cuestión: reflexiones desde América Latina (F. Wanderley, ed.): 253-282; La Paz: Centro de Investigación y de Documentación para el Desarrollo-Universidad M ayor de San Andrés (CIDES-UM SA), 0 xfam.

POU PEAU, F., 2011 - L'eau de la pachamama. Commentaires sur l'idée d'indigénéisation de la modernité. L’Homme, 198-199: 247-276.

RIST, G., 1996 - Le développement. Histoire d'une croyance occidentale, 511 pp.; París: Presses de Sciences Po.

RIVERA CUSICANQUI, S., 1992 - Ayllus y proyectos de desarrollo en el Norte de Potosí, 192 pp.; La Paz: Taller de Historia O ral Andina (THOA).

RIVIÈRE, G., 1982 - Sabaya : structures socio-économiques et représentations symboliques dans le Carangas, Bolivie, 430 pp.; París: École des hautes Études en Sciences Sociales (EHESS). Thèse de doctorat de $3^{\text {ème }}$ cycle.

RIVIÈRE, G., 2002 - Temps, pouvoir et société dans les communautés aymaras de I'altiplano (Bolivie). In: Entre ciel et terre. Climat et sociétés (E. Katz, A. Lammel \& M. Goloubinoff, eds.): 357-373; París: Institut de Recherche et de Développement (IRD), IBIS Press.

SAARESRANTA, T., 2011 - Perspectivas hacia una educación intracultural en el contexto indígena originario campesino. Tinkazos, 30: 127-144.

SALAS CARRENO, G., 2012 - Entre les mineurs, les grands propriétaires terriens et l'État: les allégeances des montagnes dans le sud des Andes péruviennes (1930-2012). Recherches amérindiennes au Q uébec, 42 (2-3): 25-37.

SIERRA, M.-T., 1997 - Esencialismo y autonomía: paradojas de las reivindicaciones indígenas. Alteridades, 7 (14): 131-143.

SVAM PA, M., 2012 - Consenso de los Commodities, Giro Ecoterritorial y Pensamiento crítico en América Latina. O bservatorio Social de América Latina (OSAL), 32: 15-38.

TICON A ALEJO, E. \& ALBO, X., 1997 - Jesús de Machaca: la marka rebelde 3. La lucha por el poder comunal, 409 pp.; La Paz: Centro virtual de Documentación e Información (CEDO IN ), Centro de Investigación y Promoción del Campesinado (CIPCA).

ULLO A, A., 2007 - La articulación de los pueblos indígenas en Colombia con los discursos ambientales, locales, nacionales y globales. In: Formaciones de indianidad. Articulaciones raciales, mestizaje y nación en América Latina ( $M$. de la Cadena ed.): 287-326; Popayán: Envion. 
UNIVERSIDAD NACIONAL «SIGLO XX», 2000 - Estatuto orgánico. Documentos ideopolíticos, 79 pp.; Llallagua: Universidad Nacional «Siglo XX» (UN SXX).

ZALLES CUETO, A., 2000 - Educación y movilidad social en la sociedad rural boliviana. Nueva Sociedad, 165:134-147. 